Thorax (1973), 28, 107.

\title{
Measurement of bronchial elastance in resected sheep lungs
}

\author{
A. J. AKHTAR, SYLVIA MERCHANT, G. J.R. MCHARDY, \\ and J. W. CROFTON
}

Department of Respiratory Diseases, City Hospital, Edinburgh

\begin{abstract}
The elastance of bronchial segments in resected sheep lungs has been measured by the following method. A balloon mounted on a probe was introduced into a bronchus of 3-4 mm diameter, the elastance of the balloon itself having been determined previously. The changes in pressure in the balloon resulting from the addition of successive small volumes of saline to the balloon were recorded, and the slope of the resulting pressure/volume curve gave the elastance of balloon and bronchus. The bronchial elastance was found by subtracting the elastance of the balloon from the combined value.

Estimates of bronchial elastance derived from repeated inflations of the balloon during a single insertion showed little variation. Considerable variation was found between bronchi in the same animal and between animals, the elastance ranging from 1.1 to $3.4 \mathrm{~cm} \mathrm{H}_{2} \mathrm{O} / \mu 1$ in the 25 bronchi studied. Repeated insertion of the balloon into the same bronchus was accompanied by a progressive increase in elastance; possible causes for this are discussed. It is hoped that the method may be applicable in man.
\end{abstract}

Endomural bronchial pressure changes during respiration have previously been measured in man by introducing a balloon on the end of a probe into a basal segmental bronchus of patients with chronic bronchitis or bronchial asthma (Crofton, Douglas, Simpson, and Merchant, 1963 ; Douglas et al., 1966). When oesophageal pressure, representing the intrapleural pressure, was recorded at the same time it was found in some wheezy patients that the ratio between the endobronchial and oesophageal pressure changes during the respiratory cycle was greater than unity. It was concluded that, at least in these patients, active contraction of bronchial muscle during expiration might be contributing to airway obstruction by adding a 'dynamic' increase in tone to a static component which remained constant throughout the respiratory cycle.

It was thought that static bronchial muscle tone might be investigated by measuring the mechanical properties of the bronchial wall; for example, muscle tone might be expected to influence the elastance of the bronchus, expressed as the change in bronchial endomural pressure per unit change in volume. We have used resected sheep lungs to evolve a method of measuring bronchial elastance, which it is hoped may be applicable in man. This report describes the method and the results of its application in the bronchi of 13 resected sheep lungs.

\section{MATERIALS AND METHODS}

The principle of the method was to insert a cylindrical balloon, mounted on a probe, into the bronchus and to calculate the combined elastance of the balloon and bronchus from the slope of the pressure/ volume curve obtained after repeated additions of small volumes of saline to the balloon. The elastance of the bronchus was then found by subtracting the previously measured elastance of the balloon.

The heart and lungs of sheep were placed after slaughter in a plastic bag containing a small quantity of isotonic saline. The experiment was begun within an hour of the death of the animal and lasted about two hours. The left lung was removed by severing the left main bronchus. (The right lung of the sheep is less convenient than the left because the right upper lobe bronchus comes off the trachea separately from the main bronchus.) The lung was placed on its side in a plastic bag containing enough isotonic saline to keep the surface moist, preliminary experiments (McHardy, 1967) with lungs suspended in a sealed glass jar having shown that varying the jar pressure between $-40 \mathrm{~cm} \mathrm{H}_{2} \mathrm{O},-20 \mathrm{~cm} \mathrm{H} \mathrm{H}_{2} \mathrm{O}$, and atmospheric, did not significantly influence the bronchial elastance. 
A metal probe previously described (Crofton et al., 1963) was used to introduce the balloon into the bronchus. The original probe had two rubber cuffs $17 \mathrm{~mm}$ apart. The distal one was immediately proximal to the tip of the probe. Clark (1969) showed that a length of latex Paul's tubing when used to form a balloon according to the original method did not behave as a true cylinder when inflated. He modified the probe by using pairs of rubber cuffs proximally and distally and tying the balloon firmly between each pair of cuffs. He showed by microscopy that the balloon then behaved as a true cylinder over the range of inflation used. Before the distal end of the balloon was tied to the cuff, the probe and balloon were filled with saline and any bubbles were carefully expelled, so that the balloon, probe, and pressure transducer formed a continuous saline-filled system. Before the experiment the balloon was fully inflated five times by the addition of saline ; this was found to minimize changes in elastance during the course of the experiment. The pressure in the balloon was measured by a fluid-filled strain gauge (Statham Instruments, type P23 De) connected to a pen recorder (Devices Instruments Ltd.).

\section{PROCEDURE}

CALIBRATION OF BALLOON Small successive volumes $(10 \mu \mathrm{l})$ were added to the balloon by means of a Vernier micrometer syringe (Burroughs Wellcome Ltd.) and the pressure was recorded at a standard time of 36 seconds after each addition (see below). A pressure/volume curve was constructed, the slope of which represented the elastance of the balloon.

In a series of preliminary experiments with sheep lungs it was found that if the volume of the balloon was allowed to fall below a certain level the balloon became 'floppy' and the slope of the pressure/volume relationship was altered (Fig. 1). Because the position of the balloon on its pressure/volume curve

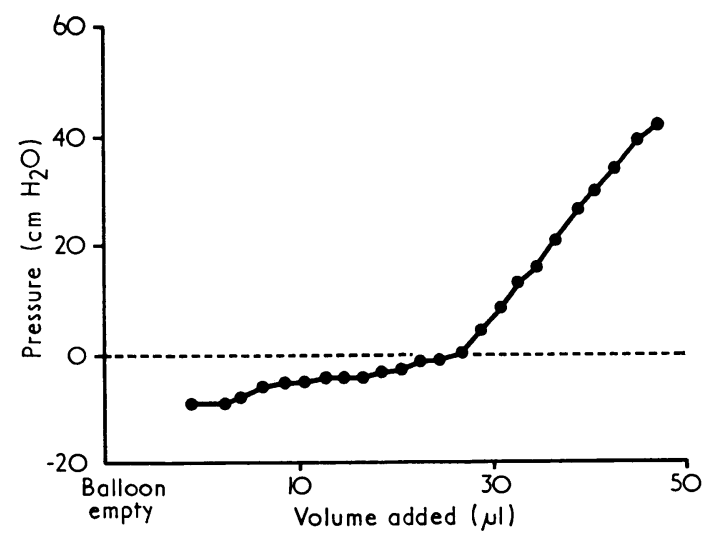

FIG. 1. Pressure/volume curve of the balloon, showing the alteration in slope below a volume of approximately $30 \mu \mathrm{l}$ and pressure of $5 \mathrm{~cm} \mathrm{H}_{2} \mathrm{O}$. was not known an accurate deduction of the elastance of the balloon from the combined elastance of $\bar{\sigma}$ balloon and bronchus could not be made. A method $\overline{\bar{S}}$ was therefore used, based on that evolved by Dr. $\Phi$ R. A. Clark in this department (Clark, 1969), in 2 which the volume of the balloon was maintained o well above the critical level throughout the experi- $\overrightarrow{0}$ ment. This was done by emptying the balloon completely into the micrometer syringe and then isolat- $\vec{\omega}$ ing it from the syringe by closing a tap. The syringe $\sigma$ was then connected to a reservoir containing saline $\overrightarrow{\vec{x}}$ and filled to a volume of $400 \mu \mathrm{l}$. The tap to the reservoir was closed and the one to the balloon was $\infty$ opened; a volume of $140 \mu$ l was then added to the $\overrightarrow{.}$ empty balloon by means of the micrometer syringe. $\overrightarrow{0}$ The balloon was now within the volumetric range 0 in which it could be considered with very little $\frac{\circ}{\partial}$ error to be a cylinder (Clark, 1969). The elastance of the balloon was then measured by adding a further $20 \mu \mathrm{l}$ to the balloon in two increments of $10 \mu \mathrm{l}$ and $\stackrel{\partial}{\mathrm{C}}$ recording the pressure after each addition. Because શِ of a slight initial decay the pressure was read at $36^{-}$ seconds after the completion of each volume incre- $\vec{\theta}$ ment, and the pressure reading after the second $\omega$ increment was used to calculate the elastance (Fig. 2). The reading recorded after the first increment was used to ensure that the pressure /volume relationship was linear.

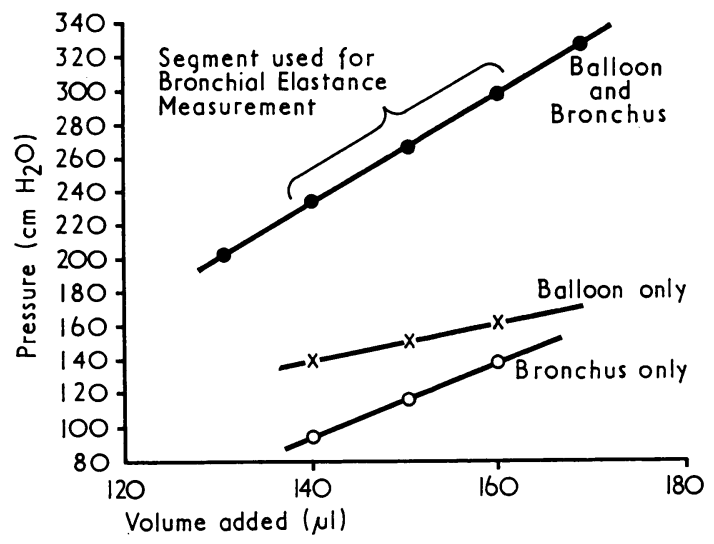

FIG. 2. Pressure/volume curve of balloon and bronchus. Elastance is calculated from the slope of each relationship.

After each elastance measurement the balloon was emptied by withdrawing fluid into the syringe in order to avoid changes in balloon volume due to $\stackrel{0}{ᄃ}$ hysteresis. To ensure complete emptying the syringe $\mathbb{E}$ plunger was pulled back five times against the resistance of the empty balloon. The elastance of $T$ the balloon was measured twice before bronchial $\stackrel{P}{1}$

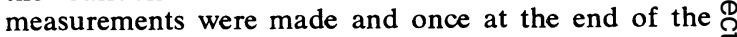
experiment to determine any change.

MEASUREMENT OF BRONCHIAL ELASTANCE Before the balloon was inserted into a bronchus it was emptied 
as described above and filled with $140 \mu \mathrm{l}$ of saline. The probe bearing the balloon was gently inserted into a bronchus of the lower lobe until the pressure was about $100 \mathrm{~cm} \mathrm{H}_{2} \mathrm{O}$ higher than before insertion; this pressure was called the post-insertional pressure. In this way it was hoped to standardize the position of the balloon in the bronchus after each insertion.

The following method was used to construct a pressure/volume curve for the balloon and bronchus combined in order to investigate whether it was linear in a range wider than that over which bronchial elastance was to be measured (Fig. 2). After the balloon had been inserted into the bronchus, saline was withdrawn into the micrometer syringe until the pressure had fallen by $100 \mathrm{~cm} \mathrm{H}_{2} \mathrm{O}$. Volume increments of $10 \mu$ l were then successively added. The pressure rose with each increment but then decayed slowly over a period, as described by Martin and Proctor (1958); because of this stress relaxation the pressure was noted 36 seconds after each increment. The increments were continued until the full range of pressure which could be recorded (approximately $200 \mathrm{~cm} \mathrm{H}_{2} \mathrm{O}$ ) had been covered. The pressure reading nearest the post-insertional pressure was noted and the pressure readings above and below it were used to measure the combined elastance of balloon and bronchus; the elastance of the balloon was then subtracted to obtain the bronchial elastance. The procedure was thrice repeated, giving four readings in all; on the repeat occasions only the readings above and below the post-insertional pressure were made, by adding two successive increments of $10 \mu \mathrm{l}$ (Fig. 3).

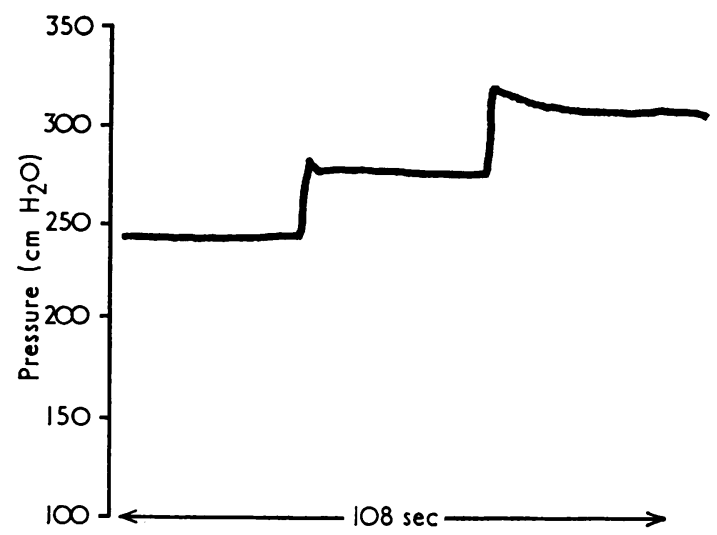

FIG. 3. Pressure record from balloon in bronchus of left lower lobe of a resected sheep lung. Each step represents the addition of $10 \mu \mathrm{l}$ saline to the balloon. Pressure readings were taken 36 seconds after each volume increment. In this instance the post-insertional pressure was $240 \mathrm{~cm} \mathrm{H}_{2} \mathrm{O}$.

REINSERTIONS When reinsertion into the same bronchus was required, the balloon was emptied and withdrawn by about $1 \mathrm{~cm}$. To ensure an actual withdrawal, the lung was held so that the end of the probe could be felt to move. The balloon was then filled with $140 \mu \mathrm{l}$ of saline and reinserted until the post-insertional pressure was the same as at the previous insertion. The measurements of bronchial elastance described above were then repeated.

COMPARISON OF BRONCHI IN THE SAME LUNG The elastance of three different bronchi in the same lung was investigated by cutting across the main bronchus quite close to where it subdivided, so that at least two segmental bronchi orifices could be clearly seen. The balloon was inserted into one of these and four elastance measurements were made in the usual way. A green dye was introduced into the bronchus by means of a second channel in the probe, while the balloon was still in position. The balloon was then emptied and withdrawn from the bronchus and the dye was washed off it. It was then refilled with 140 $\mu l$ of saline and introduced into a second visible segmental bronchus. After measurements had been made, a yellow dye was introduced into this bronchus before the probe was withdrawn. The balloon was finally inserted into a third bronchus, which was identified by cutting down with a scalpel after the measurements had been completed. The segment of bronchus surrounding the balloon was dissected out and removed. The corresponding segments in the first two bronchi were identified by inserting the balloon, filled with $140 \mu \mathrm{l}$ of saline, into each bronchus and adjusting its position so that the pressure was the same as the original post-insertional pressure. The section of the bronchus surrounding the balloon was then dissected out. Confirmatory identification of the bronchus was made by observing a high local concentration of the dye and this ensured that three different bronchi had in fact been entered.

\section{RESULTS}

Thirteen lungs were studied; in the first series of seven lungs, repeated insertions were made into one bronchus in each lung. In the second series of six lungs, single insertions were made into three different bronchi in each lung. A total of 25 bronchi were studied. In each bronchus elastance was estimated by four inflations of the balloon after each insertion.

The bronchial elastance found on the first insertion into the 25 bronchi ranged from $1 \cdot 1$ to $3.4 \mathrm{~cm} \mathrm{H} \mathrm{H}_{2} \mathrm{O} / \mu \mathrm{l}$, mean $2 \cdot 39$, SD $\pm 0.61 \mathrm{~cm} \mathrm{H}_{2} \mathrm{O} / \mu \mathrm{l}$. The mean elastance of 13 balloons was 1.06 , SD $\pm 0.22 \mathrm{~cm} \mathrm{H}_{2} \mathrm{O} / \mu \mathrm{l}$, with range $0.8-1.6 \mathrm{~cm} \mathrm{H}_{2} \mathrm{O} /$ $\mu \mathrm{l}$. There was a slight but not significant difference between the elastance of the balloons before and after the experiment (mean difference $0 \cdot 11, \mathrm{SD} \pm$ $\left.0.17 \mathrm{~cm} \mathrm{H}_{2} \mathrm{O} / \mu \mathrm{l}\right)$.

VARIATION BETWEEN INFLATIONS There was little variation between the four inflations following any insertion. In both series of experiments 
analyses of variance were made (see below) which showed that the residual variance attributable to inflations was small and not significant when compared with the variance attributable to insertions or to the differences between animals and between bronchi. The component of variance attributable to inflations was $0.05 \mathrm{~cm} \mathrm{H}_{2} \mathrm{O} / \mu \mathrm{l}$ in each series.

REPEATED INSERTIONS INTO THE SAME BRONCHUS Four (or in two instances, five) insertions were made into one bronchus in each of the seven lungs of the first series. The results are shown in Table I. A systematic tendency for elastance to

\section{T A B LE I}

BRONCHIAL ELASTANCE: EFFECT OF REPEATED INSERTIONS INTO A SINGLE BRONCHUS IN SEVEN ANIMALS

\begin{tabular}{|c|c|c|c|c|c|c|}
\hline \multirow{2}{*}{ Animal } & \multirow{2}{*}{ Insertion } & \multicolumn{5}{|c|}{ Elastance $\left(\mathrm{cm} \mathrm{H}_{2} \mathrm{O} / \mu \mathrm{l}\right)$} \\
\hline & & 1 & 2 & $\underset{3}{\text { Inflation }}$ & 4 & Mean \\
\hline A1 & $\begin{array}{l}1 \\
2 \\
3 \\
4\end{array}$ & $\begin{array}{l}2 \cdot 0 \\
2 \cdot 6 \\
3 \cdot 7 \\
5 \cdot 3\end{array}$ & $\begin{array}{l}2 \cdot 1 \\
2 \cdot 8 \\
3 \cdot 7 \\
4 \cdot 7\end{array}$ & $\begin{array}{l}2 \cdot 2 \\
2 \cdot 8 \\
3 \cdot 7 \\
4 \cdot 7\end{array}$ & $\begin{array}{l}2 \cdot 1 \\
2 \cdot 8 \\
3 \cdot 8 \\
5 \cdot 2\end{array}$ & $\begin{array}{l}2 \cdot 1 \\
2 \cdot 7 \\
3 \cdot 7 \\
4 \cdot 9\end{array}$ \\
\hline A2 & $\begin{array}{l}1 \\
2 \\
3 \\
4 \\
5\end{array}$ & $\begin{array}{l}2 \cdot 7 \\
5 \cdot 4 \\
6 \cdot 0 \\
6 \cdot 5 \\
7 \cdot 3\end{array}$ & $\begin{array}{l}3 \cdot 4 \\
5 \cdot 4 \\
6 \cdot 2 \\
6 \cdot 6 \\
7 \cdot 3\end{array}$ & $\begin{array}{l}3 \cdot 1 \\
5 \cdot 0 \\
6 \cdot 2 \\
6 \cdot 8 \\
7 \cdot 3\end{array}$ & $\begin{array}{l}3 \cdot 3 \\
5 \cdot 5 \\
6 \cdot 0 \\
6 \cdot 8 \\
7 \cdot 2\end{array}$ & $\begin{array}{l}3 \cdot 1 \\
5 \cdot 2 \\
6 \cdot 1 \\
6 \cdot 6 \\
7 \cdot 3\end{array}$ \\
\hline A3 & $\begin{array}{l}1 \\
2 \\
3 \\
4\end{array}$ & $\begin{array}{l}2 \cdot 4 \\
2 \cdot 7 \\
3 \cdot 1 \\
3 \cdot 4\end{array}$ & $\begin{array}{l}2 \cdot 4 \\
2 \cdot 7 \\
3 \cdot 4 \\
3 \cdot 5\end{array}$ & $\begin{array}{l}2 \cdot 4 \\
2 \cdot 5 \\
3 \cdot 1 \\
3 \cdot 1\end{array}$ & $\begin{array}{l}2 \cdot 4 \\
2 \cdot 5 \\
3 \cdot 1 \\
3 \cdot 4\end{array}$ & $\begin{array}{l}2 \cdot 4 \\
2 \cdot 6 \\
3 \cdot 2 \\
3 \cdot 3\end{array}$ \\
\hline A4 & $\begin{array}{l}1 \\
2 \\
3 \\
4\end{array}$ & $\begin{array}{l}2 \cdot 8 \\
3 \cdot 1 \\
3 \cdot 3 \\
3 \cdot 7\end{array}$ & $\begin{array}{l}2 \cdot 5 \\
3 \cdot 0 \\
3 \cdot 1 \\
3 \cdot 1\end{array}$ & $\begin{array}{l}2 \cdot 0 \\
2 \cdot 9 \\
3 \cdot 3 \\
3 \cdot 2\end{array}$ & $\begin{array}{l}2 \cdot 3 \\
2 \cdot 8 \\
3 \cdot 1 \\
3 \cdot 3\end{array}$ & $\begin{array}{l}2 \cdot 4 \\
2.9 \\
3 \cdot 2 \\
3 \cdot 3\end{array}$ \\
\hline A5 & $\begin{array}{l}1 \\
2 \\
3 \\
4 \\
5\end{array}$ & $\begin{array}{l}1 \cdot 5 \\
2 \cdot 6 \\
3 \cdot 7 \\
4 \cdot 0 \\
4 \cdot 5\end{array}$ & $\begin{array}{l}1 \cdot 4 \\
2 \cdot 4 \\
4 \cdot 5 \\
4 \cdot 0 \\
4 \cdot 5\end{array}$ & $\begin{array}{l}1 \cdot 4 \\
2 \cdot 2 \\
4 \cdot 0 \\
3 \cdot 9 \\
4 \cdot 5\end{array}$ & $\begin{array}{l}1 \cdot 5 \\
2 \cdot 4 \\
4 \cdot 0 \\
3 \cdot 9 \\
4 \cdot 5\end{array}$ & $\begin{array}{l}1 \cdot 4 \\
2 \cdot 4 \\
4 \cdot 0 \\
4 \cdot 0 \\
4 \cdot 5\end{array}$ \\
\hline A6 & $\begin{array}{l}1 \\
2 \\
3 \\
4\end{array}$ & $\begin{array}{l}2 \cdot 3 \\
2 \cdot 7 \\
3 \cdot 2 \\
3 \cdot 6\end{array}$ & $\begin{array}{l}1 \cdot 9 \\
2 \cdot 6 \\
3 \cdot 3 \\
3 \cdot 6\end{array}$ & $\begin{array}{l}2 \cdot 0 \\
2 \cdot 7 \\
3 \cdot 1 \\
3 \cdot 6\end{array}$ & $\begin{array}{l}2 \cdot 0 \\
2 \cdot 7 \\
3 \cdot 0 \\
3 \cdot 6\end{array}$ & $\begin{array}{l}2 \cdot 0 \\
2 \cdot 7 \\
3 \cdot 2 \\
3 \cdot 6\end{array}$ \\
\hline A7 & $\begin{array}{l}1 \\
2 \\
3 \\
4\end{array}$ & $\begin{array}{l}1.9 \\
5.2 \\
5.4 \\
5.4\end{array}$ & $\begin{array}{l}2 \cdot 2 \\
5 \cdot 0 \\
5 \cdot 3 \\
6 \cdot 3\end{array}$ & $\begin{array}{l}2 \cdot 2 \\
5 \cdot 1 \\
5 \cdot 6 \\
6.9\end{array}$ & $\begin{array}{l}2.4 \\
5.1 \\
5 \cdot 3 \\
6.9\end{array}$ & $\begin{array}{l}2 \cdot 2 \\
5 \cdot 1 \\
5 \cdot 4 \\
6 \cdot 4\end{array}$ \\
\hline
\end{tabular}

increase with successive insertions was found in all lungs (Fig. 4). The analysis of variance showed highly significant $(\mathrm{P}<0.001)$ differences between animals and between insertions. The component of variance attributable to animals was significantly $(\mathbf{P}<0.025)$ greater than that attributable to insertions.

It seemed possible that insertion itself might result in increased bronchial muscle tone, giving higher values of elastance. In further experiments a delay of 10 minutes after insertion was allowed

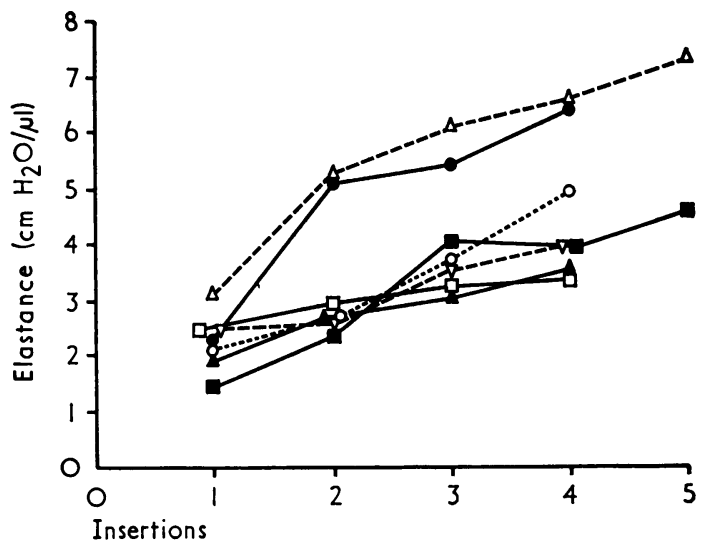

FIG. 4. Bronchial elastance in a single bronchus of each of seven lungs, showing the tendency of the elastance to rise with successive insertions of the balloon.

in the hope that the bronchus would recover its original tone, but elastance measurements after such a delay continued to show a progressive rise with each insertion.

The possibility that the balloon was being pushed further down the bronchus with each insertion, resulting in increased elastance, was next investigated. This was done in animals by dissecting out the bronchus containing the balloon and marking the position of the end of the probe. Elastance measurements were then made; the balloon was slightly withdrawn and reinserted to the same position under direct vision and the measurements were repeated. A total of four insertions was made and the elastance was again found to increase with each insertion.

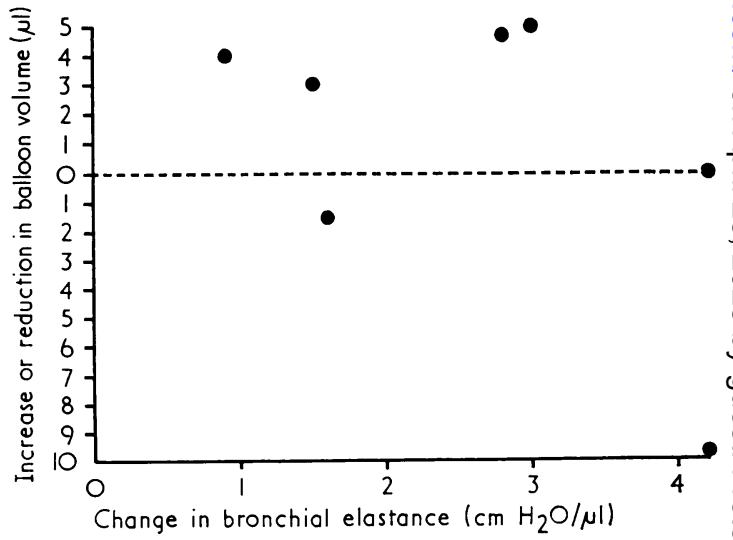

FIG. 5. The increase in bronchial elastance between the first and last of each series of insertions plotted against the increase or decrease of initial balloon volume: no relationship between the two can be seen. 
It was possible that the bronchus, after being stretched by the increasing balloon volume, did not return to its original volume between insertions and that repeated insertions might therefore cause a steady increase in volume. However, no correlation was found when the changes in initial balloon volume between the first and last of each series of insertions were plotted against the increase in elastance (Fig. 5).

VARIATION BETWEEN BRONCHI In the second series of experiments, the elastance of three bronchi in each of six lungs was measured; the results are shown in Table II. Analysis of variance showed that the elastance varied significantly between lungs $(P<0.025)$ and between bronchi in the same lung $(P<0.001)$. The variation between lungs was not significantly different from the variation between bronchi in the same lung $(P<0.25)$.

\section{T A B L E I I}

BRONCHIAL ELASTANCE MEASURED DURING A SINGLE INSERTION INTO THREE BRONCHI IN EACH OF SIX LUNGS

\begin{tabular}{|c|c|c|c|c|c|c|}
\hline \multirow{2}{*}{ Animal } & \multirow{2}{*}{ Bronchus } & \multicolumn{5}{|c|}{ Elastance $\left(\mathrm{cm} \mathrm{H}_{2} \mathrm{O} / \mu \mathrm{l}\right)$} \\
\hline & & 1 & 2 & $\underset{3}{\text { Inflation }}$ & 4 & Mean \\
\hline B1 & $\begin{array}{l}1 \\
2 \\
3\end{array}$ & $\begin{array}{l}2 \cdot 0 \\
2 \cdot 5 \\
2 \cdot 2\end{array}$ & $\begin{array}{l}2 \cdot 1 \\
2 \cdot 6 \\
2 \cdot 4\end{array}$ & $\begin{array}{l}2 \cdot 2 \\
2 \cdot 7 \\
2 \cdot 4\end{array}$ & $\begin{array}{l}2 \cdot 4 \\
2 \cdot 6 \\
2 \cdot 6\end{array}$ & $\begin{array}{l}2 \cdot 1 \\
2 \cdot 6 \\
2 \cdot 4\end{array}$ \\
\hline B2 & $\begin{array}{l}1 \\
2 \\
3\end{array}$ & $\begin{array}{l}2.4 \\
1.4 \\
3.2\end{array}$ & $\begin{array}{l}2 \cdot 6 \\
1 \cdot 5 \\
3 \cdot 3\end{array}$ & $\begin{array}{l}2 \cdot 4 \\
1 \cdot 7 \\
3 \cdot 3\end{array}$ & $\begin{array}{l}2.4 \\
1.9 \\
3 \cdot 4\end{array}$ & $\begin{array}{l}2.4 \\
1.6 \\
3.3\end{array}$ \\
\hline B3 & $\begin{array}{l}1 \\
2 \\
3\end{array}$ & $\begin{array}{l}2 \cdot 4 \\
2 \cdot 2 \\
3 \cdot 3\end{array}$ & $\begin{array}{l}1 \cdot 3 \\
2 \cdot 5 \\
3 \cdot 3\end{array}$ & $\begin{array}{l}2 \cdot 2 \\
2 \cdot 5 \\
3 \cdot 5\end{array}$ & $\begin{array}{l}2 \cdot 3 \\
2 \cdot 6 \\
3 \cdot 3\end{array}$ & $\begin{array}{l}2 \cdot 0 \\
2 \cdot 4 \\
3 \cdot 4\end{array}$ \\
\hline B4 & $\begin{array}{l}1 \\
2 \\
3\end{array}$ & $\begin{array}{l}3 \cdot 2 \\
2 \cdot 7 \\
2 \cdot 5\end{array}$ & $\begin{array}{l}3 \cdot 1 \\
2 \cdot 7 \\
2 \cdot 7\end{array}$ & $\begin{array}{l}3 \cdot 5 \\
3 \cdot 3 \\
3 \cdot 0\end{array}$ & $\begin{array}{l}3 \cdot 3 \\
3 \cdot 0 \\
3 \cdot 1\end{array}$ & $\begin{array}{l}3 \cdot 2 \\
3 \cdot 0 \\
2 \cdot 8\end{array}$ \\
\hline B5 & $\begin{array}{l}1 \\
2 \\
3\end{array}$ & $\begin{array}{l}2.3 \\
1.6 \\
2.6\end{array}$ & $\begin{array}{l}2 \cdot 7 \\
1 \cdot 4 \\
2 \cdot 6\end{array}$ & $\begin{array}{l}1.6 \\
1.5 \\
2.6\end{array}$ & $\begin{array}{l}2 \cdot 1 \\
1 \cdot 3 \\
2 \cdot 6\end{array}$ & $\begin{array}{l}2 \cdot 2 \\
1 \cdot 4 \\
2 \cdot 6\end{array}$ \\
\hline B6 & $\begin{array}{l}1 \\
2 \\
3\end{array}$ & $\begin{array}{l}1 \cdot 0 \\
2 \cdot 8 \\
2 \cdot 5\end{array}$ & $\begin{array}{l}1 \cdot 1 \\
3 \cdot 3 \\
2 \cdot 6\end{array}$ & $\begin{array}{l}1 \cdot 2 \\
3 \cdot 3 \\
2 \cdot 6\end{array}$ & $\begin{array}{l}1 \cdot 1 \\
3 \cdot 3 \\
2 \cdot 7\end{array}$ & $\begin{array}{l}1 \cdot 1 \\
3 \cdot 1 \\
2 \cdot 6\end{array}$ \\
\hline
\end{tabular}

\section{DISCUSSION}

The distensibility of bronchi has a measurable influence on the overall elastic behaviour of lungs (Mead, 1969). For this reason the measurement of bronchial elastance is of more than theoretical interest. The mechanical properties of animal bronchi and tracheae have been studied by Martin and Proctor (1958) and by Olsen, Stevens, and McIlroy (1967). The compliance of the tracheo- bronchial tree of infants has been measured by Burnard et al. (1965).

Studies of human and animal lungs by means of tantalum bronchography (Hughes, Hoppin, and Mead, 1970) have suggested that the lung expands isotopically and that the compliance of the bronchi is not greatly different from that of the lungs as a whole. The values for bronchial elastance obtained by our method are considerably larger than those which would be expected on such an argument. Preliminary experiments (McHardy, 1967) suggested that there was little effect when the lung was dissected away from bronchial segments. Anderson (1971) has compared the elastance measured by our method in segments of bronchi distended by a balloon and by direct distension using the segment itself as a balloon. In the three animals investigated she found values of the same magnitude with the balloon as those reported here. The elastances measured by direct distension were slightly less in each case but still greater than that to be expected for the lungs as a whole. This suggests that the use of the balloon does not induce a falsely high value for elastance. We are unable to explain this discrepancy between measurements made with the balloon and those made by tantalum bronchography.

The method described above gave results which were qualitatively similar to those described by Martin and Proctor (1958); in particular, the gradual fall in pressure after each volume increment is comparable to the 'delayed compliance' which they described in dog tracheae, and both phenomena may have a parallel in the slow dilatation noted in some venous beds after a volume increment (Alexander, Edwards, and Ankeney, 1953).

Although the present method allows measurements to be made only on bronchial segments of short length and diameter about $4 \mathrm{~mm}$, it has the advantage that it can be applied to bronchi visualized in intact man at bronchoscopy, as well as to the segmental bronchi of resected human lungs.

In the present experiments, repeated measurements of bronchial elastance during successive inflations of the balloon gave reproducible results, and the differences between bronchi, though statistically significant, were not great. The systematic increase in bronchial elastance with successive insertions of the balloon into the same bronchus was surprising.

It seems possible that this phenomenon is a property of the isolated sheep bronchus, as it has not been observed in later experiments with resec- 
ted human lungs and in measurements made at bronchoscopy in man (Anderson, 1969). We did not therefore wish to spend effort in investigating it further, and concluded that, in spite of this unanswered question, the results were sufficiently encouraging to justify consideration of the use of the method in man.

\section{REFERENCES}

Alexander, R. S., Edwards, W. S., and Ankeney, J. L. (1953). The distensibility characteristics of the portal vascular bed. Circulat. Res., 1, 271.

Anderson, I. M. E. (1969). Personal communication.

- (1971). Unpublished observations.

Burnard, E. D., Grattan-Smith, P., Picton-Warlow, C. G., and Grauaug, A. (1965). Pulmonary insufficiency in prematurity. Aust. paediat. J., 1, 12.

Clark, R. A. (1969). Unpublished observations.
Crofton, J., Douglas, A., Simpson. D., and Merchant, S (1963). The measurement of bronchial endomural or 'squeeze' pressure. Thorax, 18, 68.

Douglas, A., Simpson, D., Merchant, S., Crompton, G.,'and Crofton, J. (1966). The measurement of endomural bronchial (or 'squeeze') pressures in bronchitis and $\omega$ asthma. Amer. Rev. resp. Dis., 93, 693.

Hughes, J. M. B., Hoppin, F. H., and Mead, J. (1970). Relative hysteresis of air spaces and bronchi in excised lungs. Clin. Sci., 38, $31 \mathrm{P}$.

McHardy, R. (1967). Measurement of bronchial compliance in sheep's lungs. Thorax, 22, 480.

Martin, H. B., and Proctor, D. F. (1958). Pressure-volume measurements on dog bronchi. J. appl. Physiol., 13, 337. - -

Mead, J. (1969). Contribution of compliance of airways to $\overrightarrow{0}$ frequency-dependent behaviour of lungs. $J$. appl. Physiol., 26, 670.

Olsen, C. R., Stevens, A. E., and Mcllroy, M. B. (1967). Rigidity of tracheae and bronchi during muscular $\vec{c}$ constriction. J. appl. Phy siol., 23, 27. 